\title{
A Patient-Centered Prescription Drug Label to Promote Appropriate Medication Use and Adherence
}

\author{
Michael S. Wolf, PhD MPH', ${ }^{1}$, Terry C. Davis, PhD'3 , Laura M. Curtis, $\mathrm{MS}^{7}$, \\ Stacy Cooper Bailey, PhD MPH', JoAnn Pearson Knox, MSW', Ashley Bergeron, $\mathrm{MPH}^{7}$, \\ Mercedes Abbet, BA ${ }^{5}$, William H. Shrank, MSHS MD ${ }^{6}$, Ruth M. Parker, MD', and Alastair J. J. Wood, MD ${ }^{8}$ \\ 'Health Literacy and Learning Program, Division of General Internal Medicine, Feinberg School of Medicine at Northwestern University, Chicago, IL, \\ USA; ${ }^{2}$ Department of Learning Sciences, School of Education and Social Policy, Northwestern University, Evanston, IL, USA; ${ }^{3}$ Department of \\ Medicine-Pediatrics, Louisiana State University Health Sciences Center - Shreveport, Shreveport, LA, USA; ${ }^{4}$ Division of Pharmaceutical Outcomes \\ and Policy, Eshelman School of Pharmacy, University of North Carolina - Chapel Hill, Chapel Hill, NC, USA; ${ }^{5}$ NoVA Scripts Central Pharmacy, Falls \\ Church, VA, USA; ${ }^{6} \mathrm{CVS} /$ Caremark, Woonsocket, RI, USA; ${ }^{7}$ Division of General Medicine, Emory University School of Medicine, Atlanta, GA, USA; \\ ${ }^{8}$ Department of Pharmacology, Weill Cornell Medical College, New York, NY, USA.
}

BACKGROUND: Patient misunderstanding of prescription drug label instructions is a common cause of unintentional misuse of medication and adverse health outcomes. Those with limited literacy and English proficiency are at greater risk.

OBJECTIVE: To test the effectiveness of a patientcentered drug label strategy, including a Universal Medication Schedule (UMS), to improve proper regimen use and adherence compared to a current standard.

DESIGN: Two-arm, multi-site patient-randomized pragmatic trial.

PARTICIPANTS: English- and Spanish-speaking patients from eight community health centers in northern Virginia who received prescriptions from a central-fill pharmacy and who were 1) $\geq 30$ years of age, 2) diagnosed with type 2 diabetes and/or hypertension, and 3) taking $\geq 2$ oral medications.

INTERVENTION: A patient-centered label (PCL) strategy that incorporated evidence-based practices for format and content, including prioritized information, larger font size, and increased white space. Most notably, instructions were conveyed with the UMS, which uses standard intervals for expressing when to take medicine (morning, noon, evening, bedtime).

MAIN MEASURES: Demonstrated proper use of a multidrug regimen; medication adherence measured by selfreport and pill count at 3 and 9 months.

KEY RESULTS: A total of 845 patients participated in the study (85.6 \% cooperation rate). Patients receiving the PCL demonstrated slightly better proper use of their drug regimens at first exposure $(76.9 \%$ vs. $70.1 \%, p=0.06)$ and at 9 months (85.9 \% vs. $77.4 \%, p=0.03)$. The effect of the PCL was significant for English-speaking patients (OR $2.21,95 \%$ CI 1.13-4.31) but not for Spanish speakers (OR 1.19, 95\% CI 0.63-2.24). Overall, the intervention did not improve medication adherence. However, significant benefits from the PCL were found among patients with limited literacy (OR 5.08, $95 \%$ CI 1.15-22.37) and for those with medications to be taken $\geq 2$ times a day (OR 2.77, 95 \% CI 1.17-6.53).

Received April 12, 2016

Revised May 25, 2016

Accepted July 8, 2016

Published online August 19, 2016
CONCLUSIONS: A simple modification to pharmacygenerated labeling, with minimal investment required, can offer modest improvements to regimen use and adherence, mostly among patients with limited literacy and more complex regimens.

Trial Registration (ClinicalTrials.gov): NCT00973180, NCT01200849

KEY WORDS: prescription; medication; label; understanding; adherence; health literacy; clinical trial; pharmacy.

$\mathrm{J}$ Gen Intern Med 31(12):1482-9

DOI: $10.1007 / \mathrm{s} 11606-016-3816-\mathrm{x}$

(c) Society of General Internal Medicine 2016

\section{INTRODUCTION}

Many studies have reported a high prevalence of patient misunderstanding of common prescription drug label instructions, and its association with unintentional medication misuse and adverse health outcomes. ${ }^{1-4}$ Those with limited literacy skills and English proficiency (LEP) are disproportionately at risk. ${ }^{2-9}$ The manner in which physicians convey prescription instructions and pharmacy labeling practices has consequently been scrutinized as possible root causes of the confusion. ${ }^{10-14}$ This body of research has now been summarized at great length in numerous seminal reports, all recognizing the urgent need to improve written medication instructions and prescription labeling, both to promote patient safety and to improve adherence. ${ }^{10,15-17}$

In 2008, the Institute of Medicine (IOM) issued a report recognizing the need for setting standards within prescribing and dispensing practices. ${ }^{10}$ In the report, the evidence for drug labeling "best practices" was summarized, and the concept of a "Universal Medication Schedule" (UMS) was introduced. Specifically, given that an overwhelming majority of prescriptions are reportedly taken four or fewer times a day, the UMS establishes an equivalent number of standard time intervals for the prescribing and dispensing of medicine (morning, noon, evening, bedtime). This is designed to remove the previously noted variability in the manner in which prescriptions are written by physicians and transcribed by pharmacists. All 
prescriptions must instruct patients to take their medicine at one or more of these specified times, and must be described in a single standardized fashion. UMS instructions also include simplified text, the use of numeric characters instead of words to detail dose ("1" instead of "one"), and carriage returns (placing each dose on a separate line) to clearly identify every time a medicine is to be taken. ${ }^{18}$

In multiple efficacy trials, adults who were shown drug labels that included UMS instructions (e.g. "take 1 tablet in the morning and 1 tablet at bedtime") versus a current standard (e.g. "take 1 tablet twice daily") were better able to demonstrate proper dosing and spacing of medication. ${ }^{19-22}$ This has even led to a reduction in known disparities, as adults with low literacy benefited the most. These findings have since been replicated in one international $\operatorname{study}^{23}$ and among LEP patients. ${ }^{24}$ Despite extensive evidence supporting the UMS, a major limitation is that testing to date has been conducted only in hypothetical scenarios. In the present study, we tested the effectiveness of an evidence-based, patient-centered drug label strategy that included UMS instructions, in order to promote proper medication use and adherence compared to a current pharmacy best practice among actual patients following multidrug regimens. Our team capitalized on a unique opportunity to partner with a central-fill pharmacy serving eight community health centers in northern Virginia. Two sequential awards from the Agency for Healthcare Research and Quality (AHRQ) were merged into a single pragmatic trial; the first award was to study the UMS among English-speaking patients, and the second extended the evaluation to Spanish-speaking individuals.

\section{METHODS}

We conducted a two-arm, multi-site, patient-randomized pragmatic trial of a patient-centered prescription drug labeling (PCL) strategy to improve proper use and adherence. A description of the trial is provided in greater detail in a previous publication. ${ }^{25}$ The primary goal of the study was to determine whether the PCL strategy could improve 1) demonstrated proper use of prescribed drug regimens and 2) subsequent adherence compared to the current pharmacy standard. We hypothesized that this evidencebased label would improve proper use, and that it might also have a disproportionate benefit among those with limited literacy and English proficiency, but also among patients with greater regimen complexity. The outcome of medication adherence, measured via self-report and pill count, was included as an exploratory aim, as many barriers could exist that labeling would not solve (e.g. side effects, cost). The study procedures were approved by the institutional review boards (IRBs) at Northwestern University and participating community health center sites, as well as a national independent IRB service.

\section{Participants}

Study participants were patients seeking care between August 2009 and October 2012 from one of eight safety-net primary care clinics located in northern Virginia and affiliated with NoVA ScriptsCentral (NSC), a non-profit central-fill pharmacy. NSC provides a subsidized prescription drug service to vulnerable patients via courier delivery. Specifically, patients pay $\$ 5$ per prescription for mostly 90-day fill orders for a limited formulary of chronic medicines. Patients were eligible for enrollment if they 1) were 30 years of age or older, 2) had a diagnosis of type 2 diabetes and/or hypertension, 3) were taking two or more oral medications purchased through NSC, and 4) were fluent in English or Spanish. Medical directors at each clinic worked closely with NSC and gave approval for participation in the study. Exclusion criteria included 1) an uncorrectable hearing or visual impairment, 2) inability to participate due to illness, or 3) a cut-off score of 4 on the Six-Item Screener (SIS) suggesting a significant cognitive impairment. ${ }^{26}$

\section{Intervention}

The PCL intervention comprised changes to prescription drug container labeling, following only evidence-based practices for information format and content, with labels placed on 40dram bottles containing a 90-day supply of a prescription. Patients receiving the PCL had all prescriptions that were being filled for them by NSC dispensed with this new label structure. A detailed account of the evidence supporting labeling changes is described in the 2008 IOM report and also by Shrank and colleagues. ${ }^{10,25}$ The acceptability of the labeling was also supported by patient focus groups. ${ }^{21}$ Label changes included dose instructions that were written in UMS form, stating when to take a medication using one of four daily standard time intervals (morning, noon, evening, bedtime). A graphic aid was also placed in the center of the label, below the instructions, to visually display the dose (number of pills) per specified interval(s). In addition, the label prioritized patient content via large, bolded font (12 point) and increased white space; this included patient name, birth date, medication name and dose, indication, and UMS instructions. The latter was further highlighted by a light blue box pre-printed on the label paper. Content that was deemed secondary but still useful to patients as reference information was organized with attention paid to sufficient white space, and placed to the right of the primary content. The standard label arm followed a common template used by a national pharmacy chain at the time of trial initiation. Most importantly, the instructions followed a common standard not in UMS form. Figure 1 provides a sample of both the PCL and standard label. Spanish translations of the UMS instructions were undertaken previously following a rigorous, patient-centered process that involved the use of three bilingual, bicultural translators to independently translate and then reconcile any discrepancies. A full description of the translation process is available in an earlier publication. ${ }^{27}$

\section{Randomization}

A simple 1:1 randomization scheme was employed to assign patients to either the PCL or standard care study arms. Eligible 

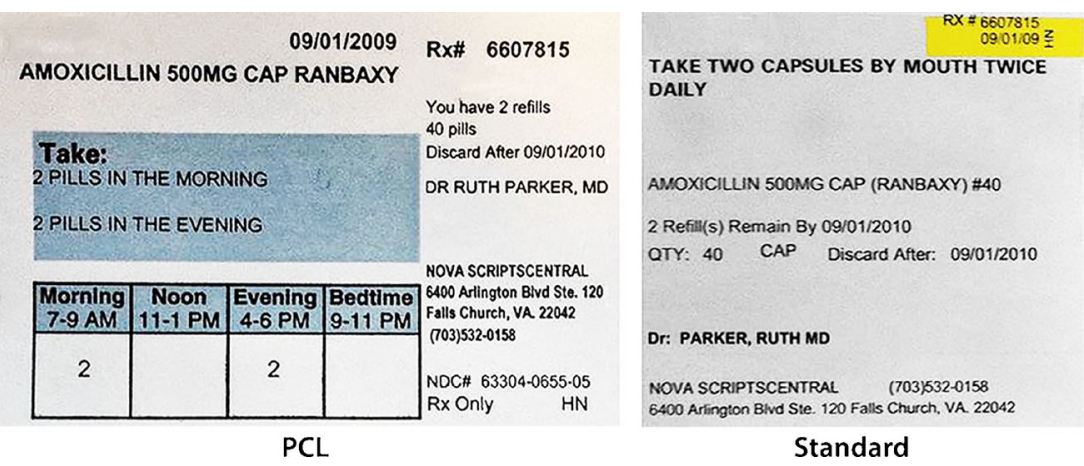

Fig. 1 Sample of patient-centered primary label using the Universal Medication Schedule (UMS).

patients were identified via pharmacy and medical records, and once consent was obtained, randomization was performed using a random number generator. Two pharmacy labeling printer systems were used; one generated the PCL label format and the other the current label standard. Both labels were programmed within the Cerner ${ }^{\circledR}$ Etreby Pharmacy Management System software. A fixed field was included to identify the printer each patient would be assigned to, and subsequently the label and instruction type they would receive for the entire course of the study.

\section{Outcomes}

The primary outcome was demonstrated proper use (yes or no) of a prescribed drug in a patient's regimen. This was measured by the patient's ability to correctly report, for each medication, all of the following: 1) how many pills taken per dose, 2) times per day a medicine was to be taken, specifying the hour of each dose, and 3) the total number of pills taken daily. This has served as a common outcome in prior studies. ${ }^{2,4,19-23}$ A regimen summary score at the patient level was also calculated, indicating whether the dosing of all medications a patient was taking was correct. The secondary outcome under study was adherence, measured via 1) self-report of missed or incorrect doses in the prior 4 days using the Patient Medication Adherence Questionnaire (PMAQ) ${ }^{28,29}$ and 2) pill count (for diabetes and hypertensive medicines). Demonstrated proper use was measured at baseline and at 3 and 9 months, whereas adherence was assessed at 3 and 9 months.

In addition, literacy skills were measured at baseline using the Rapid Estimate of Adult Literacy in Medicine $(\text { REALM })^{30}$ among English-speaking patients, and the Short Assessment of Health Literacy for Spanish Adults (SAHLSA) among LEP Spanish-speaking patients. ${ }^{31} \mathrm{We}$ also collected general sociodemographic data (age, gender, race/ethnicity, and education attainment), health status, and general prescription regimen information (self-report of number of medications taken).

\section{Analysis}

Response rates at 3- and 9-month follow-up were calculated following the American Association of Public Opinion
Research (AAPOR) guidelines. Chi-square tests were first used to compare patient-level outcomes by study arm. Generalized linear models (GLM) were used for medication level analyses separately at each time point. A generalized estimating equation (GEE) approach was used specifying a binomial family and logit link for the dichotomous outcomes. Odds ratios comparing the PCL strategy and standard label arms were calculated using robust standard error estimates in conjunction with standard repeated-measures GEE methodology. Overall intervention effects were first examined for each outcome, and models were repeated stratified by language to determine whether estimates differed between English- and Spanish-speaking participants. To determine whether the PCL effects varied by patient and medication characteristics, interaction terms for group by each of the following were included in additional models: literacy level (limited vs. adequate), number of self-reported medications taken daily $(<4,4-5$, $>5$ ), and medication-specific variables including number of times per day the medicine was taken ( 1 vs. 2 or more) and medication class (antihypertensive/diuretic, diabetes [oral], or statin). All statistical analyses were performed overall and stratified by language using STATA version 12.1 software (StataCorp LP, College Station, TX).

\section{RESULTS}

\section{Participant Flow}

A total of 851 patients in all were recruited, although only 845 had complete data and were included in the final sample (see Fig. 2). The overall cooperation rate was $85.4 \%$ among Spanish-speaking patients and $85.9 \%$ among Englishspeaking patients. At 3 months, retention rates were $60.7 \%$ among Spanish-speaking patients and $51.1 \%$ among English-speaking patients; by 9 months, the retention rates were $65.2 \%$ and $41.2 \%$, respectively. Spanish participants were more likely than English-speaking participants to complete the 9-month interview (Spanish $65 \%$, English $41 \%, p<0.001)$. Over half $(56 \%)$ of female participants completed the 9-month interview, compared to $48 \%$ of men $(p=0.03)$. Attrition rates did not differ by arm, age, education, or literacy level. 


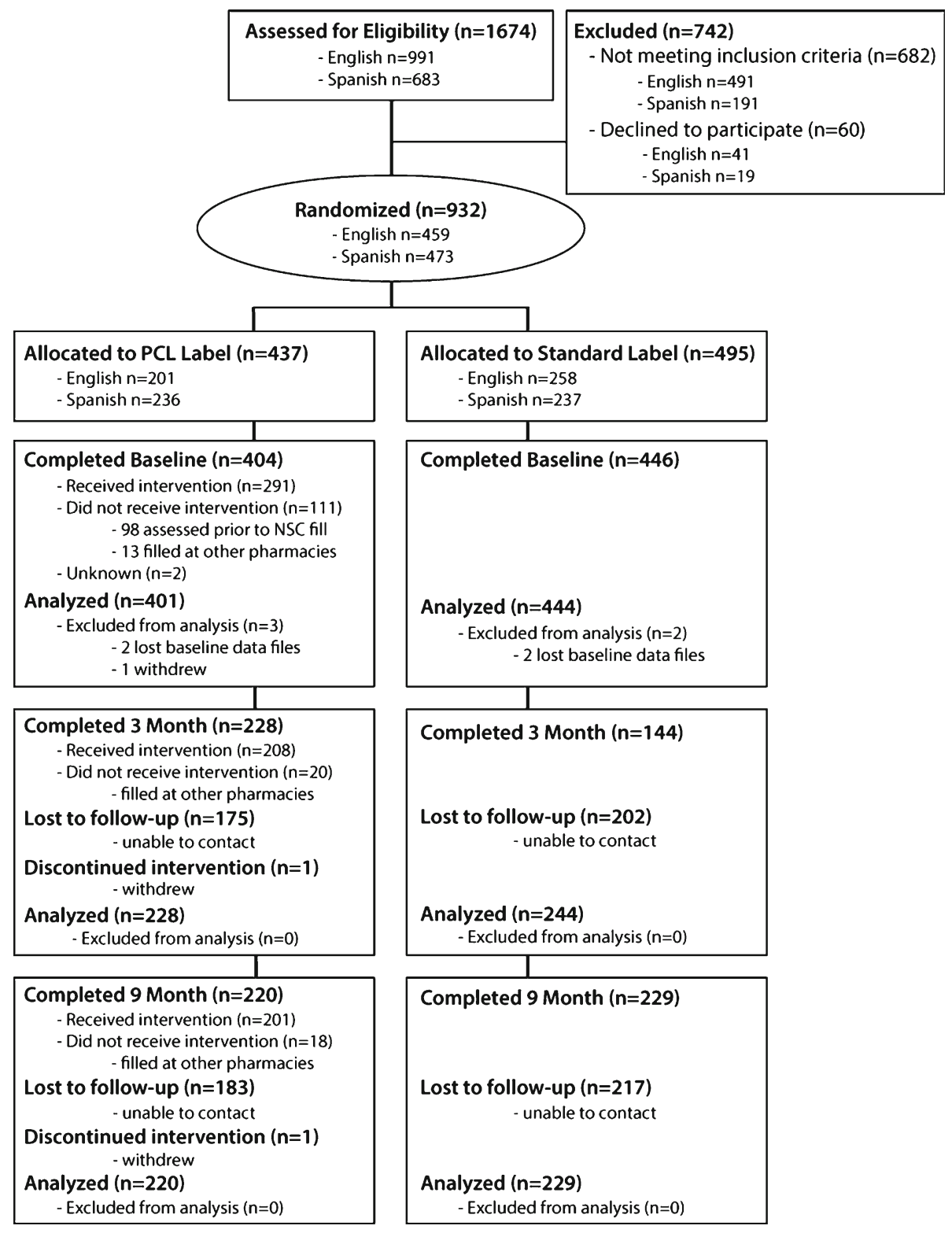

Fig. 2 CONSORT diagram.

\section{Baseline Data}

The 845 patients included in these analyses were taking a total of 2259 NSC-filled medications (1087 English, 1172 Spanish). The average regimen size at baseline, including all pharmacies, was 3.8 medications among Spanish-speaking patients and 4.6 medications among English-speaking patients. Participants are described in Table 1, stratified by both language spoken and study arm. There were differences noted by language; Spanish-speaking patients were more likely to be women $(68.3 \%$ vs. $56.2 \%, p<0.001)$ and to have less than a high school education $(61.5 \%$ vs. $24.6 \%, p<0.001)$.

\section{Outcomes}

Demonstrated Proper Use. At baseline, with the first potential exposure to the intervention, the overall rate of demonstrated proper use of all medications in patients' regimens was $71.8 \%$; the rate was slightly higher among those in the PCL arm $(76.9 \%)$ compared to those in the standard arm $(70.1 \%$, $p=0.06$ ). At 3 months, $80.3 \%$ of the sample demonstrated proper regimen use, with no differences between study arms ( $82.6 \%$ vs. $79.0 \%, p=0.35$ ). By 9 months, the overall rate of safe use was $80.8 \%$, and more patients demonstrated correct use in the PCL arm than the standard care arm $(85.9 \%$ vs. $77.4 \%, p=0.03)$. This was confirmed in medication-level GEE models; at 9 months, patients receiving the PCL were more likely to demonstrate proper use than those receiving the standard (odds ratio [OR] 1.67, $95 \%$ confidence interval [CI] $1.06-2.63, p=0.03$, Table 2). When examining the effect of the intervention by language, the PCL significantly improved proper use for English-speaking patients (OR 2.21, $95 \%$ CI 1.13-4.31, $p=0.02$ ) but not for Spanish speakers (OR 1.19, 
Table 1 Participant Characteristics Stratified by Language

\begin{tabular}{|c|c|c|c|c|c|}
\hline \multirow[t]{2}{*}{ Characteristic } & & \multicolumn{2}{|l|}{ English $(n=425)$} & \multicolumn{2}{|l|}{ Spanish $(n=420)$} \\
\hline & & Standard $(N=241)$ & PCL $(N=184)$ & Standard $(N=203)$ & PCL $(N=217)$ \\
\hline Age, mean years (SD) & $52.4(9.2)$ & $51.8(8.2)$ & $53.7(8.1)$ & $51.6(10.0)$ & $52.6(10.2)$ \\
\hline \multicolumn{6}{|l|}{ Gender, \% } \\
\hline Male & 37.7 & 41.9 & 46.2 & 35.5 & 28.1 \\
\hline Female & 62.3 & 58.1 & 53.8 & 64.5 & 71.9 \\
\hline \multicolumn{6}{|l|}{ Race/ethnicity, \% } \\
\hline Black & 23.2 & 42.7 & 50.0 & 0.5 & 0.0 \\
\hline White & 14.7 & 27.0 & 29.9 & 0.5 & 1.4 \\
\hline Hispanic & 50.3 & 3.7 & 2.7 & 98.0 & 97.7 \\
\hline Other & 11.8 & 26.6 & 17.4 & 1.0 & 0.9 \\
\hline \multicolumn{6}{|l|}{ Education, \% } \\
\hline$<$ High school & 42.9 & 25.8 & 23.0 & 63.9 & 59.3 \\
\hline High school grad/GED & 25.2 & 34.6 & 34.4 & 13.9 & 17.6 \\
\hline Some college & 18.7 & 24.2 & 24.6 & 10.9 & 14.8 \\
\hline College + & 13.2 & 15.4 & 18.0 & 11.3 & 8.3 \\
\hline \multicolumn{6}{|l|}{ Literacy, \% } \\
\hline Limited & 37.4 & 37.9 & 39.6 & 38.4 & 34.1 \\
\hline Adequate & 62.6 & 62.1 & 60.4 & 61.6 & 65.9 \\
\hline
\end{tabular}

$95 \%$ CI $0.63-2.24, p=0.59)$. Significant language-specific interactions were found between receipt of the PCL intervention and number of medications in a patient's regimen. At 3 months, Spanish-speaking patients receiving the PCL who were taking more complex drug regimens $(>5 \mathrm{Rx}$ medications) were better able to demonstrate proper use of their medications compared to their counterparts receiving the standard label (OR 5.54, $95 \%$ CI 1.09-28.07, $p=0.04$ ). This was also true among English speakers at 9 months, with those on complex regimens in the PCL arm better demonstrating proper use compared to the standard arm (OR 14.3, $95 \%$ CI 1.23$165.42, p=0.03$ ).

Regimen Adherence. Overall adherence rates by self-report at 3 and 9 months were 82.1 and $82.5 \%$, respectively, whereas rates via pill count were $33.2 \%$ and $30.8 \%$. There were no differences between study arms at 3 months (self-report: $80.9 \%$ [PCL] vs. $83.3 \%$ [standard], $p=0.49$; pill count:
$35.8 \%$ vs. $30.9 \%, p=0.32$ ) or at 9 months (self-report: $85.8 \%$ vs. $79.3 \%, p=0.07$; pill count: $33.8 \%$ vs. $28.0 \%$, $p=0.26$ ). However, in medication-level analyses, Spanishspeaking patients receiving the PCL were more likely to selfreport higher rates at 9 months (OR 2.17, $95 \%$ CI 0.99-4.73, $p=0.05$; Table 2). Significant interactions were found between study arm and daily dosing schedule and between study arm and literacy level. At 3 months, English-speaking individuals in the PCL arm were significantly more likely than those in the standard arm to be adherent (via pill count) to prescribed regimens for medications taken two or more times daily. Similar results were observed for the two arms with once-a-day medications (OR 2.77, $95 \%$ CI 1.17-6.53, $p=$ 0.02 ).

The PCL intervention demonstrated a significant benefit for patients with lower literacy skills in terms of both self-reported and objectively measured adherence via pill count at 9 months. While there were no differences in adherence by study arm

Table 2 Odds Ratios Comparing the PCL Strategy vs. Standard Care on the Outcomes of Proper Medication Use and Adherence*

\begin{tabular}{|c|c|c|c|c|c|c|c|c|c|}
\hline \multirow[t]{2}{*}{$\overline{\text { Outcome }}$} & \multicolumn{3}{|c|}{ Baseline } & \multicolumn{3}{|c|}{3 months } & \multicolumn{3}{|c|}{9 months } \\
\hline & OR & $95 \%$ CI & $P$ value & OR & $95 \% \mathrm{CI}$ & $P$ value & OR & $95 \% \mathrm{CI}$ & $P$ value \\
\hline \multicolumn{10}{|l|}{ All patients } \\
\hline Demonstrated proper use & 1.16 & $0.88-1.52$ & 0.30 & 1.19 & $0.78-1.81$ & 0.43 & 1.67 & $1.06-2.63$ & 0.03 \\
\hline $\begin{array}{l}\text { Medication adherence } \\
\text { Self-report (PMAQ) }\end{array}$ & - & - & - & 0.93 & $057-152$ & 076 & 150 & $093-274$ & 009 \\
\hline Pill count & - & - & - & 1.24 & $0.85-1.80$ & 0.27 & 1.13 & $0.75-1.71$ & 0.55 \\
\hline \multicolumn{10}{|l|}{ English } \\
\hline $\begin{array}{l}\text { Demonstrated proper use } \\
\text { Medication adherence }\end{array}$ & 1.21 & $0.78-1.88$ & 0.40 & 1.37 & $0.70-2.68$ & 0.36 & 2.21 & $1.13-4.31$ & 0.02 \\
\hline Self-report (PMAQ) & - & - & - & 1.06 & $0.51-2.19$ & 0.88 & 1.06 & $0.50-2.27$ & 0.88 \\
\hline Pill count & - & - & & 1.16 & $0.66-2.05$ & 0.61 & 1.45 & $0.74-2.81$ & 0.28 \\
\hline \multicolumn{10}{|l|}{ Spanish } \\
\hline Demonstrated proper use & 1.21 & $0.85-1.72$ & 0.28 & 1.10 & $0.64-1.90$ & 0.73 & 1.19 & $0.63-2.24$ & 0.59 \\
\hline Self-report (PMAQ) & - & - & - & 0.87 & $0.41-1.82$ & 0.71 & 2.17 & $0.99-4.73$ & 0.05 \\
\hline Pill count & - & - & - & 1.27 & $0.77-2.10$ & 0.35 & 0.93 & $0.54-1.58$ & 0.78 \\
\hline
\end{tabular}

* Standard care arm set as referent group

OR odds ratio, CI confidence interval, PMAQ Patient Medication Adherence Questionnaire 
among those with adequate literacy, patients with limited literacy who received the PCL were more likely to demonstrate proper adherence, both by self-report (OR 4.29, $95 \%$ CI $0.94-19.49, p=0.06$ ) and by pill count (OR 5.08, $95 \%$ CI $1.15-22.37, p=0.03)$, than adults with limited literacy who received standard labeling.

\section{DISCUSSION}

Our redesigned drug container label that included explicit guidance on how to self-administer prescription regimens demonstrated significant yet variable effects on proper medication use and adherence over 9 months. Specific benefits were largely limited to English-speaking patients and certain subgroups that have previously been found to be at greater risk for unsafe medication use and non-adherence: adults with low literacy and those taking more complex multi-drug regimens. Interestingly, these patients had rates of adherence that were comparable to, if not higher than, those who had adequate literacy skills, were taking once-a-day regimens, or were contending with fewer medications in their regimens. An earlier evaluation of changes to a prescription drug container and labeling did not find benefits to adherence or health outcomes. ${ }^{32,33}$ While we cannot isolate the independent benefits of the various label changes made with the PCL, the UMS is one new, evidence-based labeling component not included in the prior mentioned research investigations. To the best of our knowledge, this is only the second investigation to evaluate explicit changes to a prescription drug container label in actual use, and the first to include the UMS. However, a number of earlier studies support the acceptability and preference of the many patient-centered modifications under study. ${ }^{34-36}$

The majority of patients did not receive a benefit from the PCL, but in no instance did we find that it performed worse than standard labeling. As the intervention involved subtle modifications to pharmacy-generated labeling that could be readily put into practice, set to scale, even small increases in proper use and adherence among subgroups of consumers might yield a cost benefit. From a local perspective, the implementation of the PCL within the central-fill pharmacy used in this trial included only a one-time cost of a programmer to make the requisite changes to the labeling software allowing for the new format, and the purchase of label paper that had a pre-printed color highlight for the UMS instructions (as most pharmacies do not have color printers). Importantly, the PCL did not require any changes to typical pharmacy workflow.

Unfortunately, Spanish-speaking patients did not receive the same benefit as their English-speaking counterparts. It is possible that the translated UMS terms for times of day did not adequately account for the specific cultural backgrounds of the patients involved in our study, despite previous findings showing success in efficacy trials. ${ }^{24,37}$ Medication-related beliefs pertaining to how prescribed drugs are to be taken also could have influenced their behavior, and it is possible that the label instructions and information were less impactful. ${ }^{38,39}$ Further study is needed to better understand the unique needs of LEP patients.

\section{Limitations}

We partnered with a central-fill pharmacy that had a mandate to provide services to patients who were of low socioeconomic status and representative of the most vulnerable patient populations, by education, literacy, race/ethnicity, comorbidity, and income. These community health settings made it difficult not only to retain patients at follow-up, but also to readily access data for purposes of both follow-up and exploratory analyses examining the effects on intermediary clinical outcomes. In addition, rates of adherence were very low in the standard care arm, and despite marked gains among at-risk groups, rates were also low in the intervention arm. However, our findings are validated by other adherence studies that have documented similar rates and have highlighted known socioeconomic disparities in adherence. ${ }^{40,41}$ Further research should seek to generalize the effectiveness of the PCL among a more diverse study sample from an array of ambulatory care and pharmacy practices, not limited solely to settings serving those that are socioeconomically disadvantaged.

There are several other limitations to our evaluation. In order to maintain recruitment, we could not target only those patients with newly prescribed treatments. The majority ( $>90 \%)$ were refills at baseline, and therefore patients already had experience following these regimens. We were also unable to collect data that would have allowed us to calculate ratios of medication possession or proportion of days covered, due to the manner in which refills were generated by the central-fill pharmacy. Specifically, a change to protocols at the participating clinics did not allow for a valid recorded patient "pick-up" date, just the courier delivery date. However, we were able to monitor adherence via pill count, which is a better reflection of medication use over time than simply refill dates. ${ }^{42}$ Although our pill count outcome did not correlate well with our selfreport measure, this is a known phenomenon and is not surprising. A recent study by Agot et al. and a review of the literature across many disease contexts both found similar trends of patients self-reporting much higher adherence than observed with pill count. ${ }^{43,44}$ Yet another limitation, which also should not be surprising, is that the majority of medications taken by study participants were once-a-day (74.7\%) and twice-a-day prescriptions (24.0\%). Only $1.2 \%$ were for more complex schedules. The value of the UMS would likely be greater for medications with more dosing ambiguity, requiring spacing of daily doses (i.e. morning and evening vs. twice daily). Our findings therefore may offer only conservative estimates of the effectiveness of the PCL strategy and UMS among patients with more complicated regimens who need help in finding the most efficient daily schedule and in sustaining adherence over time.

As there were many components to the PCL, it was not possible to separate the independent contributions of each, 
especially the graphic aid from the UMS instruction itself. The latter would be easier for most pharmacies to accept and implement. Furthermore, many patients used more than one pharmacy for their medications, so the PCL strategy and UMS were likely included in only a portion of their complete $\mathrm{Rx}$ regimen, diluting the effect. Finally, our use of two different literacy measures, the REALM and SAHLSA, may have set a different threshold of literacy for English and Spanishspeaking patients, given the discordance in assessment. Although the development of the SAHLSA is derived from the REALM, and the two measures are strongly correlated, this could have impacted findings, but was a decision made at trial initiation based on options available at the time.

\section{Conclusions}

Our study is the first to test our patient-centered label strategy with the UMS in actual use. Overall, these patient-centered changes to a drug label offered some modest and targeted benefits, particularly for individuals with more limited literacy and those with polypharmacy challenges. The variable findings by language make it difficult to fully understand the potential benefits and/or challenges experienced by either patient group. In light of the lack of evidence of any detrimental effects of the PCL strategy with regard to patients' medication use, coupled with the results of previous efficacy studies, we believe that the PCL and UMS may still represent a potential practice standard with further study. Kenning and colleagues recently found the UMS to be an acceptable practice from the perspective of not only patients, but physicians and pharmacists as well. ${ }^{45}$ From a broader view, it is unrealistic to expect that merely making a basic change to the language and organization of a drug container label would be able to sustain such a formidable behavior change or improve intermediary outcomes. However, it is reasonable to think that clear, explicit labeling could contribute to a better understanding of how to organize and simplify a daily drug regimen.

The evidence is strong that current drug labeling practices pose risks to both patient safety and adherence, and research is needed to guide policies that can establish a unified set of standards across all states. California has already enacted legislation implementing many of these practices. ${ }^{46}$ Clearly, further evaluation is needed to examine how pharmacy labeling changes can benefit patients, especially those with the most complex conditions and multi-drug regimens.

Corresponding Author: Michael S. Wolf, PhD MPH; Health Literacy and Learning Program, Division of General Internal Medicine, Feinberg School of Medicine at Northwestern University, $750 \mathrm{~N}$. Lake Shore Drive, 10th Floor, Chicago, IL 60611, USA (e-mail: mswolf@northwestern.edu).

\section{Compliance with Ethical standards:}

Conflict of Interest: Dr. Wolf has previously served as a research consultant addressing the design of patient medication information for the following entities: Abbvie, Abbott Labs, Brookings Institution,
CVS/Caremark, Deborah Adler, Eli Lilly, Luto UK, Merck, and UnitedHealthcare. Dr. Bailey has also served as a research consultant to Abbvie and Merck. In addition, some authors have received grant funding from Abbvie (Davis, Parker, Wolf), Merck (Parker, Wolf), and UnitedHealthcare (Wolf). All other authors declare that they do not have a conflict of interest.

Funding: Support for this project was provided by two research grants from the Agency for Healthcare Research and Quality (AHRQ) and the Office of Behavioral and Social Sciences Research (OBSSR) at the National Institutes of Health (NIH); (RO1HS17687; RO1HS16435). Additional support was provided by a research grant from the California Endowment (20091181) and the American College of Physicians Foundation.

\section{REFERENCES}

1. Farber HJ, Capra AM, Finkelstein JA, Lozano P, Quesenberry CP, Jensvold NG, Chi FW, Lieu TA. Misunderstanding of asthma controller medications: association with nonadherence. J Asthma. 2003;40:1725.

2. Davis TC, Wolf MS, Bass PF 3rd, Thompson JA, Tilson HH, Neuberger M, Parker RM. Literacy and misunderstanding prescription drug labels. Ann Intern Med. 2006; 145:887-94.

3. Patel MJ, Khan MS, Ali F, Kazmi Z, Riaz T, Awan S, Sorathia AL. Patients' insight of interpreting prescriptions and drug labels-a cross sectional study. PLoS ONE. 2013;8:e65019.

4. Wolf MS, Curtis LM, Waite K, Bailey SC, Hedlund LA, Davis TC, Shrank WH, Parker RM, Wood AJ. Helping patients simplify and safely use complex prescription regimens. Arch Intern Med. 2011;171:300-5.

5. Serper M, Patzer RE, Reese PP, Przytula K, Koval R, Ladner DP, Levitsky J, Abecassis MM, Wolf MS. Medication misuse, nonadherence, and clinical outcomes among liver transplant recipients. Liver Transpl. 2015;21:22-8.

6. Bailey SC, Pandit AU, Curtis L, Wolf MS. Availability of Spanish prescription labels: a multi-state pharmacy survey. Med Care. 2009;47(6):707-10.

7. Sharif I, Tse J. Accuracy of computer-generated, spanish-language medicine labels. Pediatrics. 2010.

8. Westberg SM, Sorensen TD. Pharmacy-related health disparities experienced by non-English-speaking patients: impact of pharmaceutical care. J Am Pharm Assoc. 2005;45:48-54.

9. Wilson I, Schoen C, Neuman P, Strollo M, Rogers W, Chang H, Safran D. Physician-patient communication about prescription medication nonadherence: a 50-state study of America's seniors. J Gen Intern Med. 2007;22(1):6-12.

10. Institute of Medicine. In: Hernandez LM, ed. Standardizing Medication Labels: Confusing Patients Less: Workshop Summary. Washington: National Academy Press; 2008.

11. Shrank WH, Avorn J. Educating patients about their medications: the potential and limitations of written drug information. Health Aff. 2007;26:731-40.

12. Bailey SC, Persell SD, Jacobson KL, Parker RM, Wolf MS. Comparison of handwritten and electronically generated prescription drug instructions. Ann Pharmacother. 2009;43(1): 151-2.

13. Wolf MS, Shekelle P, Choudhry NK, Agnew-Blais J, Parker RM, Shrank WH. Variability in pharmacy interpretations of physician prescriptions. Med Care. 2009;47(3):370-3.

14. Shrank WH, Agnew-Blais J, Choudhry NK, Wolf MS, Kesselheim AS, Avorn J, Shekelle P. The variability and quality of medication container labels. Arch Intern Med. 2007;167(16):1760-5.

15. US Pharmacopeia. USP32. General Notices and Requirements http://www. usporg/pdf/EN/USPNF/generalNoticesandRequirementsFinalpdf [serial on the Internet]. Available from: http://www.pharmacopeia.cn/v29240/ usp29nf24s0_c1221.html. Accessed 6 July 2016.

16. California State Board of Pharmacy. Title 16-1707.5, Patient-Centered Labels on Medication Containers. [cited February 28, 2015]; Available from: http://www.pharmacy.ca.gov/laws_regs/1707_5_proposed_text.pdf. Accessed 6 July 2016

17. National Council for Prescription Drug Programs. Universal Medication Schedule White Paper. [cited March 11, 2015]; http://www.ncpdp.org/ members/pdf/201304.UMS.WhitePaper.pdf. Accessed 6 July 2016.

18. U.S. Department of Health and Human Services, Office of Disease Prevention and Health Promotion. Quick guide to health literacy, 2010. Available from http://www.health.gov/communication/literacy/quickguide/. Accessed 6 July 2016. 
19. Morrow DG, Weiner M, Deer MM, Young JM, Dunn S, McGuire $\mathbf{P}$ Murray DM. Patient-centered instructions for medications prescribed for the treatment of heart failure. Am J Geriatr Pharmacother. 2004;2:44-52.

20. Wolf MS, Davis TC, Curtis LM, Webb JA, Bailey SC, Shrank WH, Lindquist L, Ruo B, Bocchini MV, Parker RM, Wood AJ. Effect of standardized, patient-centered label instructions to improve comprehension of prescription drug use. Med Care. 2011;49(1):96-100.

21. Bailey SC, Wolf MS, Lopez A, Russell A, Chen AH, Schillinger D, Moy G, Sarkar U. Expanding the Universal Medication Schedule: a patient-centred approach. BMJ Open. 2014;4(1):e003699.

22. Kripalani S, Robertson R, Love-Ghaffari MH, Henderson LE, Praska J, Strawder A, Katz MG, Jacobson TA. Development of an illustrated medication schedule as a low literacy patient education tool. Patient Educ Couns. 2007;66:368-77.

23. Sahm LJ, Wolf MS, Curtis LM, Behan R, Brennan M, Gallwey H, Mc CS. What's in a label? An exploratory study of patient-centered drug instructions. Eur J Clin Pharmacol. 2012;68(5):777-82.

24. Bailey SC, Chen AH, Sarkar U, Schillinger D, Wolf MS. Evaluation of language-concordant, patient-centered drug label instructions. J Gen Intern Med. 2012;27:1707-13.

25. Shrank WH, Parker R, Davis T, Pandit AU, Knox JP, Moraras P Rademaker A, Wolf MS. Rationale and design of a randomized trial to evaluate an evidence-based prescription drug label on actual medication use. Contemp Clin Trials. 2010;31(6):564-71.

26. Callahan CM, Unverzagt FW, Hui SL, Perkins AJ, Hendrie HC. Six-item screener to identify cognitive impairment among potential subjects for clinical research. Med Care. 2002;40:771-81.

27. Bailey SC, Hasnain-Wynia R, Chen AH, Sarkar U, Schoua-Glusberg A Lindquist LA, Schillinger D, Wolf MS. Developing multilingual prescription instructions for patients with limited English proficiency. J Health Care Poor Underserved. 2012;23:81-7.

28. DeMasi RA, Graham NM, Tolson JM, Pham SV, Capuano GA, Fisher RL, Shaefer MS, Pakes GE, Sawyerr GA, Eron JJ Jr. Correlation between selfreported adherence to highly active antiretroviral therapy (HAART) and virologic outcome. Adv Ther. 2001;18(4):163-73.

29. Wolf MS, Davis TC, Osborn CY, Skripkauskas S, Bennett CL, Makoul G. Literacy, self-efficacy, and HIV medication adherence. Patient Educ Couns. 2007;65(2):253-60.

30. Davis TC, Long SW, Jackson RH, Mayeaux EJ, George RB, Murphy PW, Crouch MA. Rapid estimate of adult literacy in medicine: a shortened screening instrument. Fam Med. 1993;25:391-5.

31. Lee SY, Bender DE, Ruiz RE, Cho YI. Development of an easy-to-use Spanish Health Literacy test. Health Serv Res. 2006;41:1392-412.

32. Shrank WH, Gleason PP, Canning C, Walters C, Heaton AH, Jan S, Patrick A, Brookhart MA, Schneeweiss S, Solomon DH, Avorn J, Choudhry NK. Can improved prescription medication labeling influence adherence to chronic medications? An evaluation of the Target pharmacy label. J Gen Intern Med. 2009:24:570-8.
33. Shrank WH, Patrick A, Gleason PP, Canning C, Walters C, Heaton AH, Jan S, Brookhart MA, Schneeweiss S, Solomon DH, Wolf MS, Avorn J, Choudhry NK. An evaluation of the relationship between the implementation of a newly designed prescription drug label at Target pharmacies and health outcomes. Med Care. 2009;47:1031-5.

34. Zargarzadeh AH, Law AV. Design and test of preference for a new prescription medication label. Int J Clin Pharm. 2011;33:252-9.

35. Mohan A, Riley MB, Boyington D, et al. Development of a patientcentered bilingual prescription drug label. J Health Commun. 2013; 18(suppl 1):49-61.

36. Mohan A, Riley B, Schmotzer B, Boyington DR, Kripalani S. Improving medication understanding among Latinos through illustrated medication lists. Am J Manag Care. 2014;20:e547-55.

37. Bailey SC, Agarwal N, Sleath B, Gumusoglu S, Wolf MS. Improving drug labeling and counseling for limited English proficient adults. J Health Care Poor Underserved. 2011;22:1131-43.

38. Wisnivesky JP, Krauskopf $\mathbf{K}$, Wolf MS, Wilson EA, Sofianou A, Martynenko M, Halm EA, Leventhal H, Federman AD. The association between language proficiency and outcomes of elderly patients with asthma. Ann Allergy Asthma Immunol. 2012;109:179-84.

39. Manias E, Williams A. Medication adherence in people of culturally and linguistically diverse backgrounds: a meta-analysis. Ann Pharmacother. 2010;44:964-82.

40. Shacham E, Lian M, Onen NF, Donovan M, Overton ET. Are neighborhood conditions associated with HIV management? HIV Med. 2013;14:624-32.

41. Parada H, Horton LA, Cherrington A, Ibarra L, Ayala GX. Correlates of medication nonadherence among Latinos with type 2 diabetes. Diabetes Educ. 2012;38:552-61.

42. Lee LK, Grace KA, Foster TG, Crawley MJ, Erowele GI, Sun HJ, Turner PT, Sullenberger LE, Taylor AJ. How should we measure medication adherence in clinical trials and practice? Ther Clin Risk Manag. 2007;3:685-90.

43. Agot K, Taylor D, Corneli AL, Wang M, Ambia J, Kashuba AD, Parker C, Lemons A, Malahleha M, Lombaard J, Van Damme L. Accuracy of selfreport and pill count measures of adherence in the FEM-PrEP clinical trial: implications for future HIV prevention trials. AIDS Behav. 2015;19:743-51.

44. Garber MC, Nau DP, Erickson SR, Aikens JE, Lawrence JB. The concordance of self-report with other measures of medication adherence: a summary of the literature. Med Care. 2004;42(7):649-52.

45. Kenning C, Protheroe J, Gray N, Ashcroft D, Bower P. The potential for using a Universal Medication Schedule (UMS) to improve adherence in patients taking multiple medications in the UK: a qualitative investigation. BMC Health Serv Res. 2015;15:94.

46. California State Board of Pharmacy. Title 16-1707.5, Patient-Centered Labels on Medication Containers. [cited April 6, 2015); Available from: http://www.pharmacy.ca.gov/laws_regs /1707_5_proposed_text.pdf. Accessed 6 July 2016 